\title{
O distribuciji prostih brojeva
}

\author{
Zrinka Franušić, Nikola Pavlinić
}

\section{Sažetak}

Prosti brojevi su jednostavan matematički pojam uz koji se vežu mnoga otvorena pitanja. U radu ćemo ponoviti važna svojstva prostih brojeva i dotaknuti se nekih neriješenih problema, posebice onih vezanih uz distribuciju prostih koja nas vode čak do velike Riemannove slutnje]

Ključni pojmovi: prost broj, testiranje prostosti, Teorem o prostim brojevima, Riemannova slutnja

\section{1 Što su prosti brojevi?}

Prosti ili prim brojevi jedan su od fundamentalnih pojmova u matematici. Učenici se s tim pojmom susreću već u 5 . razredu osnovne škole i nauče da je svaki prirodan broj veći od 1 prost broj ako nema djeljitelja većeg od 1 i manjeg od sebe samog. Još kažemo da je broj prost ako su mu jedini djelitelji 1 i on sam. Prirodan broj veći od 1 koji nije prost naziva se složen broj, stoga broj 1 nije niti prost niti složen. Svaki složen broj može se prikazati kao umnožak prostih. Na primjer, $84=2 \cdot 2 \cdot 3 \cdot 7$. Posebno je zgodno rastav složenog broja na proste faktore vizualizirati stablom faktorizacije kao na Slici 1 .

Gledajući stablo faktorizacije pada nam na pamet usporedba između složenih (sastavljenih) brojeva i molekula, te prostih (nerastavljivih) brojeva i atoma. To svojstvo da svaki prirodan broj veći od 1 možemo prikazati kao umnožak prostih brojeva, pri čemu uzimamo da se faktorizacija prostog broja sastoji samo od njega samog, i to na jedinstven način, izuzetno je važno i dano je u tvrdnji koja se naziva Osnovni teorem aritmetike.

Ovaj rad je potpomogla Hrvatska zaklada za znanost projektom br. 6422 . 


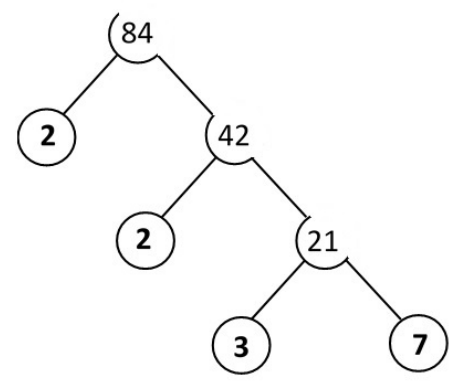

Slika 1: Stablo faktorizacije

Teorem 1 (Osnovni teorem aritmetike). Faktorizacija svakog prirodnog broja $n$ većeg od 1 na proste faktore je jedinstvena do na poredak prostih faktora.

Prirodno pitanje koje nam se dalje nameće jest koliko je velik skup prostih brojeva. Odgovor na to pitanje znali su još i stari Grci. Naime, u 9. knjizi Euklidovih Elemenata (3. st. pr. Kr.) nalazimo iskaz i jednostavan dokaz tvrdnje o brojnosti skupa prostih brojeva.

Teorem 2 (Euklid). Prostih brojeva ima beskonačno mnogo.

Dokaz. Pretpostavimo suprotno, tj. da je skup prostih brojeva konačan. Neka su su $p_{1}=2<p_{2}=3<\ldots<p_{r}$ svi prosti brojevi. Broj $n=p_{1} p_{2} \cdots p_{r}+1$ očito je veći od 1 i nije djeljiv niti s jednim od brojeva $p_{1}, \ldots, p_{r}$. Stoga postoji prost broj $q, q \neq p_{1}, \ldots, p_{r}$, koji dijeli broj $n$. Dakle, pronašli smo prost broj $q$ koji ne pripada skupu $\left\{p_{1}, \ldots, p_{r}\right\}$ što je kontradikcija s pretpostavkom te zaključujemo da je skup prostih brojeva beskonačan.

Postoji još mnogo drugih dokaza gornjeg teorema koji su zasnovani na tvrdnjama iz različitih matematičkih grana kao što su matematička analiza, topologija, itd., a za njih su zaslužni poznati matematičari poput Eulera, Goldbacha, Furstenberga, Kummera. Na primjer, Euler kao argument da je skup svih prostih brojeva $\mathcal{P}$ beskonačan koristi činjenicu da je red

$$
\sum_{p \in \mathcal{P}} \frac{1}{p}
$$


divergentan. Naime, može se dokazati da je $\sum_{p \leq y, p \in \mathcal{P}} \frac{1}{p}>\ln \ln y-1$ za svaki realan broj $y \geq 2$, iz čega direktno slijedi da je red divergentan.

\section{Ispitivanje prostosti}

Sljedeći problem kojeg je razumno razmotriti jest onaj kako provjeriti je li dani prirodan broj $n$ prost ili složen. Pristupimo li po definiciji, trebat će ispitati ima li broj $n$ nekog prostog djelitelja manjeg od $n$. Lako se može pokazati da je dovoljno provjeriti postoji li prost djelitelj manji od $\sqrt{n}$. Naime, vrijedi sljedeća tvrdnja.

Propozicija 1. Neka je $n$ složen broj. Tada postoji prost djelitelj od $n$ koji je manji ili jednak od $\sqrt{n}$.

Dokaz. Pretpostavimo da je $n=p \cdot k$, gdje je $p$ najmanji prost faktor od $n$. Tada je $k \geq p$ pa je $n \geq p^{2}$, odnosno $\sqrt{n} \geq p$.

Stoga bi u svrhu ispitivanja prostosti bilo korisno imati listu prostih brojeva manjih od nekog zadanog prirodnog broja $n$. Ako je $n$ "dovoljno malen" postoji vrlo učinkovit algoritam pomoću kojeg možemo kreirati takvu listu - tzv. Eratostenov $\emptyset^{1}$ sito. To je postupak u kojem s liste brojeva od 2 do $n$ brišemo najprije sve prave višekratnike broja 2 najmanjeg prostog broja. Uočimo da su ti obrisani brojevi složeni jer su djeljivi s 2 i strogo veći od 2. Najmanji "neobrisan" broj veći od 2 je 3 - sljedeći prost broj. Zatim s liste brišemo sve prave višekratnike broja 3 i zaključujemo da je sljedeći prost broj 5. Ponavljajući postupak, na listi će nakon konačno mnogo koraka ostati samo prosti brojevi.

\begin{tabular}{|c|c|c|c|c|c|c|c|c|c|c|c|c|c|c|c|c|c|c|c|c|c|c|}
\hline & & & & & & & & & & \multicolumn{4}{|c|}{ brisanje višekratnika od 2} & & & & & & & & & \\
\hline & & & & & & & & & & & 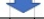 & & & & & & & & & & & \\
\hline \multirow{3}{*}{\multicolumn{2}{|c|}{\begin{tabular}{l|l}
2 & \\
\end{tabular}}} & \begin{tabular}{|l|}
5 \\
\end{tabular} & \begin{tabular}{l|l}
7 & \\
\end{tabular} & 9 & 11 & 13 & 15 & \begin{tabular}{|l|}
17 \\
\end{tabular} & 19 & 21 & $23 \mid$ & 25 & 27 & 29 & 31 & 33 & 35 & 37 & 39 & 41 & \begin{tabular}{|l|l|}
43 \\
\end{tabular} & 45 \\
\hline & & & & & & & & & \multicolumn{5}{|c|}{ brisanje višekratnika od 3} & & & & & & & & & \\
\hline & & & & & & & & & & & 5 & & & & & & & & & & & \\
\hline \multirow{3}{*}{\multicolumn{2}{|c|}{2}} & \begin{tabular}{|c|}
5 \\
\end{tabular} & 7 & & 11 & 13 & & 17 & 19 & & 23 & 25 & & 29 & 31 & & 35 & $37 \mid$ & 39 & 41 & 43 & \\
\hline & & & & & & & & & \multicolumn{5}{|c|}{ brisanje višekratnika od 5} & & & & & & & & & \\
\hline & & & & & & & & & & & $\infty$ & & & & & & & & & & & \\
\hline 2 & \begin{tabular}{|l|l|} 
& \\
\end{tabular} & 5 & 7 & & \begin{tabular}{|l|}
11 \\
\end{tabular} & \begin{tabular}{|l|}
13 \\
\end{tabular} & & \begin{tabular}{|l|l}
17 \\
\end{tabular} & \begin{tabular}{|l|}
19 \\
\end{tabular} & & \begin{tabular}{|l|}
23 \\
\end{tabular} & & & \begin{tabular}{|l|}
29 \\
\end{tabular} & \begin{tabular}{|l|}
31 \\
\end{tabular} & & & \begin{tabular}{|l|l|}
37 \\
\end{tabular} & \begin{tabular}{|l|}
39 \\
\end{tabular} & 41 & \begin{tabular}{|l|l|}
43 \\
\end{tabular} & \\
\hline
\end{tabular}

Slika 2: Eratostenovo sito za određivanje prostih brojeva $\leq 45$

Na Slici 2 "prosijani" su svi prosti brojevi manji od 45 i to u samo 3 koraka. Zbog Propozicije1]jasno je da će u koraku "brisanja višekratnika od $p$ ", $p^{2}$ biti prvi pobrisani višekratnik (jer su oni manji već pobrisani

\footnotetext{
${ }^{1}$ Eratosten, starogrčki matematičar, 3. st. pr. Kr.
} 
$\mathrm{u}$ prethodnim koracima). U našem primjeru, kako je $45<7^{2}$, nakon brisanja višekratnika od 5 ostaju samo prosti brojevi. Prije korištenja računala na ovaj način bili su popisani svi prosti brojevi manji od $10^{7}$.

Ako želimo ispitati je li neki jako velik broj $n$ prost, metoda dijeljenja sa svim prostim brojevima manjim ili jednakim od $\sqrt{n}$ je vrlo neefikasna prvenstveno zbog toga jer proste brojeve manje ili jednake od $\sqrt{n}$ nije moguće naći u nekom "razumnom" vremenu. Stoga se danas koriste različiti testovi prostosti koji se dijele na vjerojatnosne i determinističke. Razlog nastajanju mnogih algoritama koji ispituju je li neki broj prost ili ne je jednim dijelom u ljudskoj želji za pronalaženjem sve većih prostih brojeva ali i zbog njihove konkretne primjene u ICT-u (informacijsko - komunikacijskim tehnologijama). Naime, sigurnost nekih sustava za kriptiranje informacija upravo leži u težini faktorizacije brojeva koji su produkt dva (velika) tajna prosta broja.

Najveći poznati prost broj u ovom trenutku je $2^{77232917}$ - 1 (siječanj 2018.), broj koji u decimalnom zapisu ima 23249425 znamenaka. Za predodžbu o veličini toga broja, napomenimo da bi nam za zapis bilo potrebno 12917 kartica teksta. (Kartica predstavlja mjernu jedinicu za izračunavanje količine teksta $u$ dokumentu a sastoji se od $1800=60 \cdot 30$ znakova.) Ovaj gigantski prost broj spada u tzv. Mersenneove proste brojeve, tj. u proste brojeve oblika $2^{p}-1$ gdje je $p$ prost broj. Najsvježiji podatci o pronalascima velikih prostih bojeva mogu se naći na stranicama projekta nazvanog GIMPS (Great Internet Mersenne Prime Search). On obuhvaća volontere i entuzijaste diljem svijeta koji sudjeluju u potrazi za velikim prostim Mersenneovim brojevima (https://www.mersenne.org/).

Postoje još mnogi drugi zanimljivi oblici prostih brojeva kao što su $n ! \pm 1$ i $n \sharp \pm 1$, pri čemu $n \sharp$ označava umnožak svih prostih brojeva manjih ili jednakih $n$. Brojevi takvih oblika su zanimljivi jer za njih postoje efikasni determinististički testovi prostosti. Nadalje, posebnu primjenu u kriptografiji javnog ključa imaju i prosti brojevi $p$ takvi da je $2 p+1$ isto prost, npr. $p=11$ i $2 p+1=23$. Oni su nazvani Sophieini prosti u čast Marie-Sophie Germain ${ }^{2}$.

\section{Teorem o prostim brojevima}

Lako smo ustanovili da prostih brojeva ima beskonačno mnogo, no postavlja se pitanje postoji li neka pravilnost u njihovom pojavljivanju. Odgovor na pitanje krije se iza naslova ovog odjeljka, Teorem o prostim brojevima, iza kojeg stoji priča o distribuciji prostih brojeva.

Već na relativno malom uzorku opažamo (vidi Sliku 22 da postoje susjedni prosti brojevi koji su vrlo blizu jedan drugog, kao na primjer 5

\footnotetext{
${ }^{2}$ Marie-Sophie Germain, francuska matematičarka, 1776. - 1831.
} 
i 7, 11 i 13, 17 i 19, 29 i 31, itd. Dva uzastopna neparna broja koja su prosta nazivaju se prosti brojevi blizanci. Poznata slutnja kaže:

Slutnja 1. Postoji beskonačno mnogo prostih brojeva blizanca.

Najveći poznati par prostih brojeva blizanaca je 2996863034895 . $2^{1290000} \pm 1$, pronađen u rujnu 2016. godine (prema [7]), a svaki od brojeva ima 388342 znamenke. Zanimljivost vezana uz Slutnju 1] jest i $\mathrm{u}$ tome što je poznato da red

$$
\sum_{p, p+2 \in \mathcal{P}}\left(\frac{1}{p}+\frac{1}{p+2}\right),
$$

gdje je $\mathcal{P}$ skup svih prostih brojeva, konvergira (tzv. Brunov ${ }^{3}$ teorem). Ovo bi značilo da, ako je Slutnja 1 istinita, skup svih prostih brojeva blizanaca čini jedan "mali beskonačan" skup.

S druge strane uzastopni prosti brojevi mogu biti i prilično udaljeni što možemo zaključiti iz sljedeće tvrdnje.

Propozicija 2. Za svaki prirodan broj $n$ postoji $n$ uzastopnih složenih brojeva.

Dokaz. Uvjerimo se da je

$$
(n+1) !+2,(n+1) !+3, \ldots,(n+1) !+n,(n+1) !+n+1
$$

niz od $n$ složenih brojeva. Zaista, $2|(n+1) !+2,3|(n+1)$ ! $+3, \ldots$, $n+1 \mid(n+1) !+n+1$.

Nakon ovoga što smo vidjeli u prethodnim razmatranjima jasno nam je da ne možemo očekivati da će prosti brojevi pojavljivati u nekom pravilnom ritmu. Čak i činjenice da se u prvih sto prirodnih brojeva nalazi 25 prostih, u intervalu $\left\langle 10^{7}-100,10^{7}\right\rangle$ njih 9 , dok se $u$ intervalu $\left\langle 10^{7}, 10^{7}+100\right\rangle$ nalaze samo 2 prosta broja, mogu na prvi pogled djelovati obeshrabrujuće. Ipak, distribucija prostih brojeva je na neki način pravilna.

Broj prostih brojeva koji su manji ili jednaki od nekog danog realnog broja $x$ označava se s $\pi(x)$. Na Slici 3 prikazani su grafovi funkcije $x \mapsto \pi(x)$ na tri intervala $[0,100],[0,1000]$ i $[0,1000000]$. Na prvoj slici lijevo se lijepo vidi stepeničasta struktura grafa funkcije $\pi$, što je sasvim očekivano. No, na posljednjoj slici graf funkcije $\pi$ izgleda gladak iz razloga što se na njemu stepeničasta struktura ne primijeti golim okom. Ono što nas zanima jest je li moguće tu prekidnu funkciju $\pi$, odnosno,

\footnotetext{
${ }^{3}$ Viggo Brun, norveški matematičar, 1885. - 1978.
} 

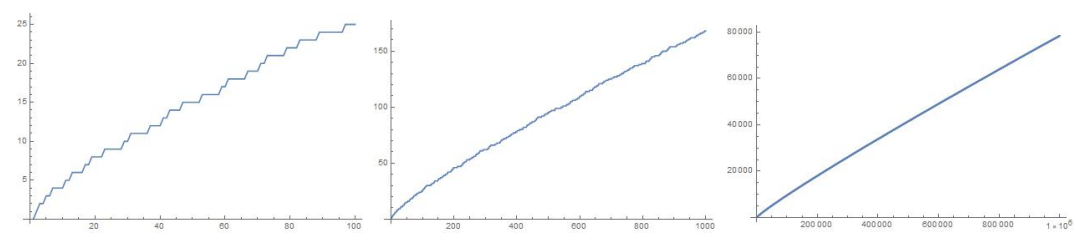

Slika 3: Grafovi funkcije $x \mapsto \pi(x)$ za $x \leq 10^{2}, 10^{3}, 10^{6}$

nazovimo ju, skalinadu prostih brojeva zamijeniti nekom glatkom funkcijom koja bi ju dobro aproksimirala. Smatramo da je potraga za tom glatkom aproksimacijom počela prije dva stoljeća kad je mladi Gaus: 4 eksperimentalno otkrio jednu takvu glatku funkciju. Godine 1791., u dobi od samo 14 godina, Gauss je dobio knjigu koja je sadržavala logaritme brojeva manjih od $10^{7}$ i tablicu svih prostih brojeva do 10009 te uskoro uočio da bi se $\pi(x)$ mogao dobro aproksimirati kvocijentom

$$
\frac{x}{\ln x}=f(x)
$$

gdje je $\operatorname{s} \ln x$ označen prirodni logaritam broja $x$. Umjesto funkcije $f$ broj prostih brojeva manjih od nekog $x$ može se aproksimirati i pomoću funkcije $g$ dane $\mathrm{s}$

$$
g(x)=\frac{x}{2 \cdot(\text { broj znamenaka od }\lfloor x\rfloor)},
$$

pri čemu je $\lfloor x\rfloor$ najveće cijelo od $x$ (tj. najveći cijeli broj koji nije veći od $x$ ). Zaista, broj znamenaka od $\lfloor x\rfloor \mathrm{u}$ bazi 10 je najmanji cijeli broj (strogo) veći od $\log \lfloor x\rfloor$ i $\ln x=\ln 10 \cdot \log x$ pa se $f(x)=\frac{x}{\ln x}$ ugrubo može aproksimirati s $g(x)$.

Dosta kasnije, 1849. godine, u svom pismu njemačkom astronomu J. F. Enckeu, Gauss je predložio još jednu bolju aproksimaciju funkcijom $L i$ koja je dana $\mathrm{s}$

$$
L i(x)=\int_{2}^{x} \frac{d t}{\ln t},
$$

a poznata pod nazivom logaritamsko integralna funkcija ili logaritamski integral. Međutim Gauss svoj rezultat nije obavio (objavljen je posthumno 1863.). U Tablici 1 prikazane su konkretne vrijednosti funkcija aproksimacija $g(x)=\frac{x}{2 \cdot(\text { broj znamenaka od }\lfloor x\rfloor)}, f(x)=\frac{x}{\ln x}$ i $\operatorname{Li}(x)=$ $\int_{2}^{x} \frac{d t}{\ln t}$ te apsolutne pogreške njihovih aproksimacija.

Prethodna zapažanja eksperimentalne prirode dio su zakonitosti raspodjele prostih brojeva, odnosno funkcije $\pi$, koju objašnjava tvrdnja

\footnotetext{
${ }^{4}$ Johann Carl Friedrich Gauss, njemački matematičar, 1777. - 1855.
} 


\begin{tabular}{|c|c|c|c|c|c|c|c|}
\hline$x$ & $\pi(x)$ & $g(x)$ & $f(x)$ & $\operatorname{Li}(x)$ & $e r r_{g}$ & $e r r_{f}$ & $e r r_{L i}$ \\
\hline 9 & 4 & 4.5 & 4.1 & 4.7 & 0.5 & 0.1 & 0.7 \\
\hline 99 & 25 & 24.8 & 21.5 & 28.9 & 0.2 & 3.5 & 3.9 \\
\hline 999 & 168 & 166.5 & 144.6 & 176.4 & 1.5 & 23.4 & 8.4 \\
\hline 9999 & 1229 & 1249.9 & 1085.6 & 1245.0 & 20.9 & 143.4 & 16 \\
\hline 99999 & 9592 & 9999.9 & 8685.8 & 9628.7 & 407.9 & 906.2 & 36.7 \\
\hline 999999 & 78498 & 83333.3 & 72382.3 & 78626.4 & 4835.3 & 6115.7 & 128.4 \\
\hline
\end{tabular}

Tablica 1: Aproksimacije od $\pi(x)$ i njihove apsolutne pogreške

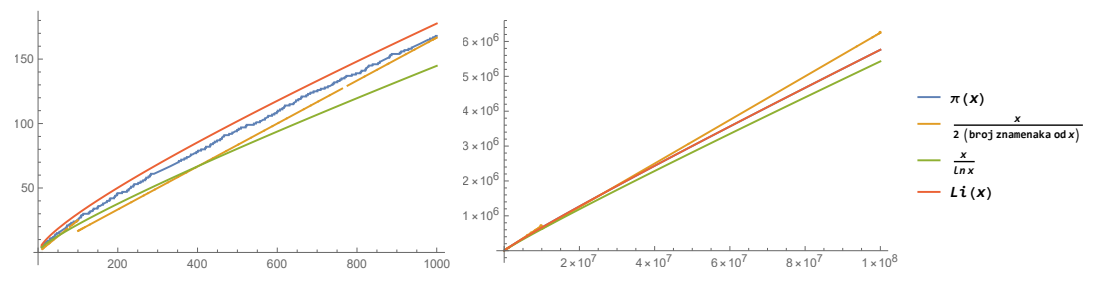

Slika 4: Aproksimacije od $\pi(x)$

poznata pod nazivom Teorem o prostim brojevima ili kratko PNT (od engl. Prime Number Theorem):

Teorem 3 (Teorem o prostim brojevima).

$$
\lim _{x \rightarrow \infty} \frac{\pi(x)}{\frac{x}{\ln x}}=1 .
$$

Tvrdnja Teorema 3 opisuje tzv. asimptotsko ponašanje funkcije $\pi$ i kaže da je $\pi$ asimptotski jednaka ili asimptotski ekvivalentna funkciji $f$ što se kratko zapisuje kao

$$
\pi(x) \sim f(x) .
$$

Isto vrijedi i za funkciju $L i(x)$ jer je

$$
\lim _{x \rightarrow \infty} \frac{\frac{x}{\ln x}}{\int_{2}^{x} \frac{d t}{\ln t}}=\{\text { L'Hôspitalovo pravilo }\}=\lim _{x \rightarrow \infty} \frac{\frac{\ln x-1}{\ln x}}{\frac{1}{\ln x}}=\lim _{x \rightarrow \infty} \frac{\ln x-1}{\ln x}=1 .
$$

Teorem 3 dokazali su 1896. godine Jacques Hadamard i Charles Jean de la Vallée-Poussin, neovisno jedan o drugome, oslanjajući se na Riemannovu 5 ideju o povezanosti prostih brojeva s tzv. Riemannovom zeta-funkcijom kompleksne varijable, $\zeta$, o kojoj ćemo ukratko nešto reći u sljedećem odjeljku.

\footnotetext{
${ }^{5}$ Bernhard Riemann, njemački matematičar, 1826. - 1866.
} 


\section{Riemannova slutnja}

Teorem 3 govori o asimptotskoj aproksimaciji funkcije $x \mapsto \pi(x)$ funkcijom $x \mapsto \frac{x}{\ln x}$ što je ekvivalentno tvrdnji da je $n$-ti prost broj $p_{n}$ asimptotski jednak $n \ln n$, tj. $p_{n} \sim n \ln n$, no ne kaže ništa o pogrešci te aproksimacije.

Slutnja 2. Za svaki $\varepsilon>0$, postoji $n_{0} \in \mathbb{N}$ takav da je

$$
|\pi(n)-\operatorname{Li}(n)|<n^{\frac{1}{2}+\varepsilon}
$$

za sve $n \in \mathbb{N}, n>n_{0}$.

Iskazana slutnja kaže da je greška aproksimacije broja svih prostih brojeva manjih ili jednakih od nekog prirodnog broja $n, \pi(n)$, pomoću $\operatorname{Li}(n)$ u suštini $\sqrt{n}$. Nadalje, ova slutnja koliko god na prvi pogled izgleda jednostavno, ona to nipošto nije. Štoviše, ekvivalentna je jednom od najpoznatijih otvorenih problema u matematici - Riemannovoj slutnji. Riemannova zeta-funkcija $s \mapsto \zeta(s)$ se definira pomoću apsolutno konvergentnog reda

$$
\zeta(s)=\sum_{i=1}^{\infty} \frac{1}{n^{s}},
$$

za sve kompleksne brojeve $s$ čiji je realni dio veći od 1. Sam je Riemann pokazao da je ovu funkciju moguće analitički proširiti na sve kompleksne brojeve $s, s \neq 1$. Može se pokazati da funkcija $\zeta$ ima nultočke u $s=-2,-4,-6, \ldots$ što su tzv. trivijalne nultočke zeta-funkcije. Sva istraživanja u vezi Riemannove zeta-funkcije u posljednjih stotinjak godina, uglavnom su se bavila problemom lociranja skupa njenih netrivijalnih nultočaka pri čemu je glavni cilj dokazati sljedeću glasovitu slutnju koju je dao sam Riemman.

Slutnja 3 (Riemannova slutnja). Sve netrivijalne nultočke Riemannove zeta-funkcije $\zeta$ nalaze se na pravcu $\operatorname{Re} s=\frac{1}{2}$.

Još uvijek se malo zna o skupu nultočaka Riemannove zeta-funkcije. Do sada je pokazano da se netrivijalne nultočke moraju nalaziti unutar tzv. kritične pruge $0<\operatorname{Re}(s)<1$.

Bez dubljeg poniranja u problem distribucije prostih brojeva, za slutnje 2 i 3 na prvi pogled možemo reći kako nemaju ništa zajedničkog. Ipak, proste brojeve i funkciju $\zeta$ veže sljedeća formula

$$
\zeta(s)=\prod_{p \in \mathcal{P}} \frac{1}{1-p^{-s}},
$$


gdje je $\mathcal{P}$ skup svih prostih brojeva, a naziva se Eulerova produktna formula.

Postoje još mnoge slutnje povezane s prostim brojevima i njihovom distribucijom (Goldbachova slutnja, slutnje o Mersennovim brojevima, o Fermatovim brojevima, o Sophieinim brojevima, itd.). Neke od njih su vrlo lako shvatljive, čak i osnovnovnoškolcima, dok druge razumiju samo znanstvenici. Mi smo istaknuli samo dvije, vrlo lako razumljivu o prostim brojevima blizancima (Slutnja 1) i vrlo tešku Riemannovu (Slutnja 3). Na kraju možemo zaključiti kako o prostim brojevima, tom elementarnom matematičkom pojmu, znamo još vrlo malo i kako oni predstavljaju gotovo neiscrpan izvor za istraživački rad. Koliko posla nas čeka najbolje je iskazao David Hilbert ${ }^{6}$ koji je rekao: - Ako se probudim nakon tisuću godina, moje prvo pitanje bi bilo: Je li dokazana Riemannova slutnja?

\section{Literatura}

[1] A. Dujella, Uvod u teoriju brojeva (skripta), https://web.math.pmf .unizg.hr/ duje/utb/utblink.pdf

[2] J. C. Lagarias, An Elementary Problem Equivalent to the Riemann Hypothesis, http://www.math.1sa.umich.edu/ lagarias/doc/ elementaryrh.pdf

[3] B. Mazur, W. Stein, Prime Numbers and the Riemann Hypothesis, Cambridge University Press, 2016.

[4] B. Širola, Distribucija prim brojeva i Riemannova zeta-funkcija; prvi dio, math.e, br. 13, http://e.math.hr/zeta/index.html

[5] Prime number, https://en.wikipedia.org/wiki/Prime_number\#Formulas_ for_primes

[6] Riemann hypothesis, https://en.wikipedia.org/wiki/Riemann_hypothesis

[7] The Largest Known Primes, http://primes.utm.edu/primes/page.php?id=122213

\footnotetext{
${ }^{6}$ David Hilbert, njemački matematičar, 1862. - 1943.
} 
Zrinka Franušić

Sveučilište u Zagrebu, Prirodoslovno-matematički fakultet, Matematički odsjek, Bijenička cesta 30, Zagreb

E-mail adresa: fran@math.hr

Nikola Pavlinić

student, Sveučilište u Zagrebu, Prirodoslovno-matematički fakultet, Matematički odsjek, Bijenička cesta 30, Zagreb

E-mail adresa: nikola.pavlinic@yahoo.com 